\title{
Remote ischemic conditioning: from bench to bedside
}

\author{
Shiang Yong Lim ${ }^{1}$ and Derek John Hausenloy ${ }^{2 *}$ \\ O'Brien Institute, Department of Surgery, University of Melbourne, St Vincent's Hospital, Melbourne, VIC, Australia \\ ${ }^{2}$ The Hatter Cardiovascular Institute, University College London Hospital and Medical School, London, UK
}

\author{
Edited by: \\ J. Kevin Shoemaker, The University of \\ Western Ontario, Canada \\ Reviewed by: \\ Zeljko Dujic, University of Split School \\ of Medicine, Croatia \\ Bijan Ghaleh, Université Paris Est \\ Créteil, France \\ Earl Noble, The University of Western \\ Ontario, Canada \\ *Correspondence: \\ Derek John Hausenloy, The Hatter \\ Cardiovascular Institute, University \\ College London Hospital and Medical \\ School, 67 Chenies Mews, WC1E \\ 6HX London, UK. \\ e-mail:d.hausenloy@ucl.ac.uk
}

Remote ischemic conditioning $(\mathrm{RIC})$ is a therapeutic strategy for protecting organs or tissue against the detrimental effects of acute ischemia-reperfusion injury (IRI). It describes an endogenous phenomenon in which the application of one or more brief cycles of non-lethal ischemia and reperfusion to an organ or tissue protects a remote organ or tissue from a sustained episode of lethal IRI. Although RIC protection was first demonstrated to protect the heart against acute myocardial infarction, its beneficial effects are also seen in other organs (lung, liver, kidney, intestine, brain) and tissues (skeletal muscle) subjected to acute IRI. The recent discovery that RIC can be induced non-invasively by simply inflating and deflating a standard blood pressure cuff placed on the upper arm or leg, has facilitated its translation into the clinical setting, where it has been reported to be beneficial in a variety of cardiac scenarios. In this review article we provide an overview of RIC, the potential underlying mechanisms, and its potential as a novel therapeutic strategy for protecting the heart and other organs from acute $|R|$.

Keywords: remote ischemic preconditioning, remote ischemic perconditioning, remote ischemic postconditioning ischemia-reperfusion injury

\section{INTRODUCTION}

Coronary heart disease (CHD) is the leading cause of morbidity and mortality worldwide (Lloyd-Jones et al., 2009). Despite optimal therapy, patients with CHD still suffer significant morbidity and mortality. As such, novel therapeutic strategies for protecting the heart against the detrimental effects of acute ischemiareperfusion injury (IRI), the major pathological consequence of $\mathrm{CHD}$, are required to improve clinical outcomes in patients with CHD.

In this regard, the phenomenon of ischemic conditioning may provide an endogenous strategy for protecting the heart against acute IRI. Murry et al. (1986) first described the phenomenon of ischemic preconditioning (IPC) in which the application of brief cycles of non-lethal ischemia and reperfusion to the heart reduced subsequent myocardial infarct size in the canine heart. The drawback of this therapeutic strategy is the requirement for the intervention to be applied prior to the index ischemic event, which in the case of an acute myocardial infarction (MI) is impossible to predict. However, the introduction of ischemic postconditioning in 2003 (Zhao et al., 2003), a phenomenon in which the process of myocardial reperfusion is interrupted by several short-lived episodes of ischemia, overcomes this problem, and can be applied at the onset of myocardial reperfusion in patients presenting with an acute MI. However, both IPC and ischemic postconditioning require an intervention to be applied to the heart directly which may not be feasible in all clinical settings. In this regard, remote ischemic conditioning (RIC) may provide a noninvasive endogenous therapeutic strategy for protecting the heart against acute IRI.

Remote ischemic conditioning describes the cardioprotective effect elicited from applying one or cycles of non-lethal ischemiareperfusion to an organ or tissue remote from the heart. It was originally described by Przyklenk et al. (1993), who demonstrated that the application of brief occlusions and reperfusion of the circumflex coronary artery dramatically reduced the size of the MI arising from a sustained occlusion of the left anterior descending coronary artery. This form of intramyocardial cardioprotection across coronary territories was then extended beyond the heart such that the latter could be protected by applying the RIC stimulus to organs and tissues remote from the heart (Kanoria et al., 2007; Hausenloy and Yellon, 2008; Tapuria et al., 2008; Candilio et al., 2011). Furthermore, experimental studies found that it was possible to protect non-cardiac organs and tissues from acute IRI. As such RIC represents a form of systemic protection against acute IRI, which has been recently translated into the clinical setting, with the discovery that the RIC stimulus could be non-invasively induced using a standard blood pressure cuff placed on the upper arm or leg (Kharbanda et al., 2002). Crucially, the timing of the RIC stimulus can accommodate most clinical settings of acute IRI, as it has been reported to protect the organ or tissue whether applied prior to (termed remote ischemic preconditioning, RIPC; Przyklenk et al., 1993), after the onset of ischemia (termed remote ischemic perconditioning; Schmidt et al., 2007), or even at the time of reperfusion (termed remote ischemic postconditioning, RIPost; Kerendi et al., 2005; Figure 1). This review article provides an overview of RIC as a protective phenomenon, the underlying mechanisms and its recent translation into the clinical arena.

\section{APPLYING THE REMOTE ISCHEMIC CONDITIONING STIMULUS}

The original experimental study describing RIC demonstrated intramyocardial cardioprotection across different coronary artery territories (Przyklenk et al., 1993). However, soon after this discovery it was demonstrated that the heart could be protected by a 


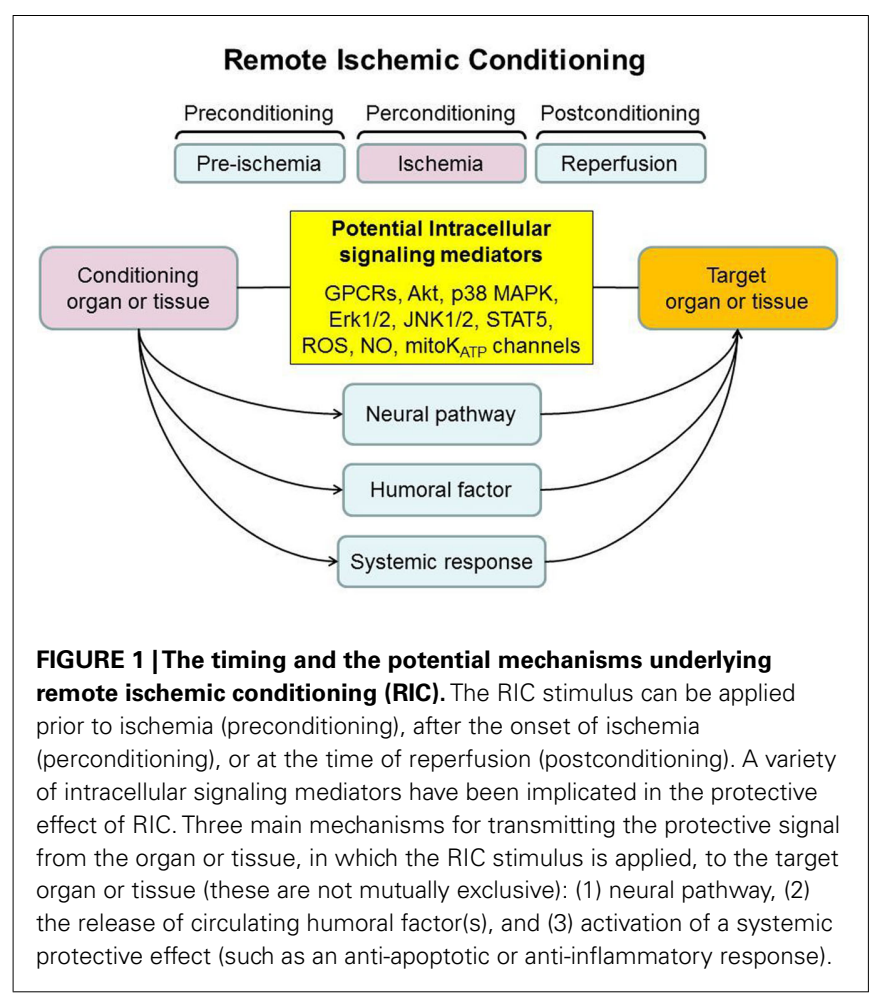

RIC stimulus applied to an organ remote from the heart such as the kidney (McClanahan et al., 1993).

\section{KIDNEY}

McClanahan et al. (1993) demonstrated for the first time that a brief period of renal ischemia and reperfusion induced by renal artery occlusion and reflow significantly reduced myocardial infarct size in the rabbit. It is of interest that Gho et al. (1996) subsequently showed that $15 \mathrm{~min}$ of renal artery occlusion followed by $10 \mathrm{~min}$ of reperfusion reduced myocardial IRI in rats under hypothermic conditions but not normothermic conditions. Similar findings were also demonstrated in a pig model of acute myocardial IRI by the same research group (Verdouw et al., 1996). These findings suggest that remote renal preconditioning may be temperature-sensitive, an observation that warrants further investigation. Subsequent mechanistic studies have implicated the involvement of adenosine (Pell et al., 1998; Takaoka et al., 1999), ATP-sensitive potassium channels ( $\left.\mathrm{K}_{\mathrm{ATP}}\right)$ channels (Pell et al., 1998; Diwan et al., 2008b), angiotensin $A_{1}$ receptors (Singh and Chopra, 2004), erythropoietin (Diwan et al., 2008b), NFкB (Diwan et al., 2008b; Kant et al., 2008), hypoxia-inducible factor (Kant et al., 2008), PPAR $\alpha$ and $\gamma$ (Lotz et al., 2011) in mediating the protective effect of remote renal preconditioning (see Mechanisms Underlying RIC).

\section{SMALL INTESTINE}

Gho et al. (1996) first demonstrated that a 15-min occlusion of the anterior mesenteric artery could limit MI size in a rat model of IRI, a finding which was confirmed in a recent study (Tapuria et al., 2008). Unlike RIC induced by brief renal ischemia, the experimental study performed by Verdouw et al. (1996) found that 15 min of mesenteric ischemia followed by $10 \mathrm{~min}$ of reperfusion protected the pig heart from subsequent IRI under both normothermic and hypothermic conditions. Heidbreder et al. (2008) linked the cardioprotective effect of remote intestinal preconditioning to the activation of p38 MAPK, ERK1/2, and JNK1/2 within the intestinal tissue but not the heart. This result may suggest the activation of local, but not the target organ, MAPK proteins to be an essential event for remote intestinal preconditioning (Heidbreder et al., 2008). Pro-survival kinase activation within the heart in response to remote organ preconditioning has been reported in several recent studies (see Mechanisms Underlying RIC).

\section{LIVER}

A few experimental studies have investigated the liver as a site for applying a RIC stimulus. Ates et al. (2002) first showed that $10 \mathrm{~min}$ of hepatic ischemia followed by $10 \mathrm{~min}$ of reperfusion could render the kidney resistant to subsequent IRI. Similarly, RIC induced by occlusion and reflow of the common hepatic artery and portal vein was demonstrated to attenuate gastric mucosal lesion induced by prolonged IRI, a protective effect which appeared to be mediated by the cyclooxygenase pathway and the activation of sensory afferent nerves (Brzozowski et al., 2004a). In addition to sensory nerves, Brzozowski et al. (2004b) also demonstrated that the protection induced by RIC of liver was attenuated in vagotomized rats suggesting an important role of vagal nerves in the brain-gut axis. Moreover, the gastroprotection afforded by RIC of liver was shown to be comparable to those induced by RIC of the myocardium and the direct stomach IPC (Brzozowski et al., 2004a,b).

\section{BRAIN}

As a vital organ that is susceptible to ischemic injury, the brain is not the most suitable choice as a site for applying a RIC stimulus. An early porcine study showed that 10 or $30 \mathrm{~min}$ of brain ischemia with reperfusion, induced by elevating the intracranial pressure, did not protect the heart from subsequent acute myocardial IRI (de Zeeuw et al., 2001). On the contrary, Valen's group showed that sustained brain ischemia (without reperfusion) induced by bilateral internal carotid permanent ligation effectively reduced MI and improved cardiac function in mice (Tokuno et al., 2002; Schulte et al., 2004). Although the reason for this discrepancy remains unclear, the differences in animal species, degree of ischemic stimulus, and type of brain ischemia may explain these contradictory results. It is interesting that this is one of the first experimental studies to demonstrate protection elicited with an episode of ischemia alone in the absence of reperfusion.

\section{LIMB}

The above experimental studies were dependent on the RIC stimulus being invasively applied to a non-cardiac organ. However, the clinical application of RIC would require a less invasive method for applying the RIC stimulus. In this regard, Birnbaum et al. (1997) made the critical observation that briefly restricting blood flow to skeletal muscle of the lower limb and pacing the gastrocnemius leg muscle prior to an acute coronary artery occlusion was able to reduce the subsequent myocardial infarct size by $65 \%$ in the rabbit heart. A less invasive method of inducing hindlimb ischemia as a RIC stimulus was described by Oxman et al. (1997) 
who demonstrated that applying a tourniquet to the hindlimb to induce $10 \mathrm{~min}$ of limb ischemia reduced reperfusion arrhythmias in a rat heart following a sustained ischemic insult. Since then, a number of experimental studies have confirmed the use of lower limb as a site for applying an RIC stimulus given it ease of access and the fact that it can be applied using a simple tourniquet. In general, limb RIC can be achieved by either tourniquet application to the limb or direct occlusion of the femoral artery, and has been shown to be effective and reproducible in reducing injury of other organ in both animals and human (Tapuria et al., 2008). The ability to induce RIC using limb ischemia and reperfusion facilitated the translation of RIC into the clinical setting (see Clinical Application).

\section{THE TARGETS OF REMOTE ISCHEMIC CONDITIONING HEART}

The cytoprotective phenomenon of RIC was first described in the heart by Przyklenk et al. (1993) and has since been extended to other organs and tissues (Kanoria et al., 2007; Hausenloy and Yellon, 2008; Tapuria et al., 2008). The cardioprotective end points conferred by RIC include infarct size reduction, improvement of ATP recovery post-ischemia (Takaoka et al., 1999), antiarrhythmia (Oxman et al., 1997), and improvement of ventricular contractile function (Kharbanda et al., 2002). The mechanisms underlying the cardioprotective effect of RIC involve multiple intricate endogenous signaling pathways (see Mechanisms Underlying RIC for detail). In brief, pre-clinical studies have provided first evidence to implicate the activation of adenosine (Pell et al., 1998), bradykinin-2 (Schoemaker and van Heijningen, 2000), opioid (Patel et al., 2002), angiotensin-1 (Singh and Chopra, 2004), and $\mathrm{CB}_{2}$ endocannabinoid (Hajrasouliha et al., 2008) receptors, opening of $\mathrm{K}_{\mathrm{ATP}}$ channels (Pell et al., 1998), calcitonin gene-related peptide (CGRP; Tang et al., 1999), signaling reactive oxygen species (Weinbrenner et al., 2004), noradrenaline (Oxman et al., 1997), nitric oxide (Wang et al., 2001), and heat shock proteins (HSPs; Tanaka et al., 1998).

\section{BRAIN}

Stroke as a result of cerebral ischemia or intracranial hemorrhage is the second leading cause of mortality and disability worldwide. An elegant study by Jensen et al. (2011) found that RIPC of the limb reduced brain edema, hemorrhage, and neuronal damage caused by hypothermic circulatory arrest in pig, and these beneficial effects were associated with significant improvement of neurological function. In a rat model of focal cerebral ischemia, neuroprotection was also evident in animals subjected to either RIPC (Ren et al., 2008) or RIPost (Ren et al., 2009) of the limb.

\section{KIDNEY}

Acute kidney injury due to acute IRI is a frequent cause of morbidity and mortality following a number of medical conditions and operative procedures. Renoprotection by RIC was first demonstrated by Ates et al. (2002) who showed that brief liver ischemia significantly reduced the biochemical (TNF $\alpha$ and tissue thiobarbituric acid-reactive substances) and histopathological markers of renal ischemic injury. Similar renoprotection was reported using limb ischemia, induced by brief infrarenal artery occlusion, as the
RIC stimulus (Lazaris et al., 2009). This is in agreement with a recent study which reported renoprotection by remote limb preconditioning via an adenosine-independent mechanism (Wever et al., 2011). Interestingly, the author also showed that bilateral RIPC was more effective than unilateral RIPC in reducing kidney injury suggesting that the threshold of protection may be determined by the volume/mass of conditioned tissue (Wever et al., 2011).

\section{LIVER AND PANCREAS}

Remote ischemic conditioning also has the potential to protect the liver from IRI. In animal model of hepatic IRI, limb RIC has been shown to reduce liver injury by improving hepatic blood flow, reducing serum aminotransferase levels, maintaining mean arterial pressure, and reducing neutrophil adhesion and cell death (Kanoria et al., 2006; Tapuria et al., 2009). Subsequent mechanistic studies have implicated heme oxygenase-1 (HO-1; Lai et al., 2006; Tapuria et al., 2009), nitric oxide (Abu-Amara et al., 2011a), and eNOS (Abu-Amara et al., 2011b) as the potential mediators of RICinduced liver protection. Peralta et al. (2001) have demonstrated that brief hepatic ischemia resulted in less neutrophil infiltration, less oxidative damage, and reduced vascular leakage in the pancreas following hepatic IRI, possibly by suppressing systemic TNF $\alpha$ release from the liver, and thus preventing adhesion molecule P-selectin upregulation. This finding may suggest a therapeutic potential of RIC in pancreatic diseases such as pancreatitis.

\section{LUNG}

During coronary artery bypass graft surgery the lung is subjected to acute IRI, a scenario which can be reproduced experimentally by repeated coronary artery occlusion and reperfusion to induce pulmonary IRI. Using this experimental model, Xia et al. (2003) showed that RIC of the limb preserved lung function in sheep. Furthermore, RIC also reduced lung damage following liver IRI (Peralta et al., 2001) or liver transplantation (Fernandez et al., 2002). More recently, RIPC through intermittent limb ischemia has also been reported to mitigate lung injury (inflammation, oxidative stress, leukocyte infiltration, edema) resulting from hemorrhagic shock and resuscitation via a HO-1 dependent manner (Jan et al., 2011). In addition to these secondary lung injuries, RIC can also protect lung from direct IRI as determined by improved lung function and oxygenation capacity, and reduced pulmonary hypertension (Waldow et al., 2005).

\section{GASTROINTESTINAL TRACT}

Remote ischemic conditioning induced gastroprotection was first illustrated by Brzozowski et al. (2004a) using a rat model of gastric IRI. The authors showed that RIC applied to the heart or liver significantly reduced gastric mucosal lesions, improved gastric blood flow, increased mucosal prostaglandin $\mathrm{E}_{2}$ production, and suppressed plasma proinflammatory cytokines (IL-1 $\beta$ and $\mathrm{TNF} \alpha$ ) levels (Brzozowski et al., 2004a,b). Furthermore, Dickson et al. (2002) have demonstrated that coronary effluent of ischemic preconditioned rabbit hearts contained humoral factor(s) that improved jejunum resistance to ischemic injury through the activation of opioid receptors and opening of $\mathrm{K}_{\mathrm{ATP}}$ channels. Others have shown that RIC also reduced intestinal injury resulting from 
hepatic IRI (Peralta et al., 2001) and anastomotic insufficiency (Holzner et al., 2011).

\section{SKELETAL MUSCLE AND SKIN FLAP}

Several experimental studies have demonstrated the cytoprotective effect of RIC on muscle flaps. Pre-clinical studies have illustrated a protective effect of RIC against tissue necrosis of epigastric adipocutaneous flaps (Kuntscher et al., 2003a,b) and skeletal muscles such as cremaster (Kuntscher et al., 2002, 2003b; Wang et al., 2004), gastrocnemius (Eberlin et al., 2009), latissimus dorsi, gracilis, and rectus abdominis muscle flaps (Addison et al., 2003; Moses et al., 2005). The protection was demonstrated to be associated with improved microcirculation and endothelium function, reduced leukocyte adhesion and accumulation, and preserved ATP content (Addison et al., 2003; Kuntscher et al., 2003b; Wang et al., 2004).

\section{MECHANISMS UNDERLYING RIC}

A better understanding of the cellular and molecular mechanisms underlying RIC may allow us to exploit the protective effect pharmacologically. In general, the mechanisms underlying the phenomenon of RIC can be considered as three inter-related events (Kanoria et al., 2007; Hausenloy and Yellon, 2008; Tapuria et al., 2008): (1) the initial events occurring in the remote organ or tissue in response to the RIC stimulus. The application of brief episodes of IR to the remote organ or tissue is believed to generate endogenous autocoids or factors which can protect target organ or tissue from injury. (2) The protective signal which is conveyed from the remote organ or tissue to the target organ or tissue. The transmission of the protective signal may be multifactoral comprising blood-borne factor(s), neuronal mechanisms, and/or systemic responses. (3) The events occurring in the target organ or tissue which confer the protective effect.

The intracellular signaling pathways recruited in the organ or tissue in which the RIC stimulus is applied and the target organ or tissue which has been protected are presumed to be similar to those recruited in direct IPC and ischemic postconditioning. There are a number of different signaling mediators including G-protein cell surface coupled receptors (adenosine, bradykinin, opioids, angiotensin), PKC, reactive oxygen species, nitric oxide, Akt, Erk1/2, p38 MAPK, and STAT5 (Hausenloy and Yellon, 2008; Heusch et al., 2012; Figure 1).

\section{NEURONAL PATHWAY}

Several experimental studies have implicated a neuronal pathway as mediating the connection between the remote conditioned organ or tissue to the protected organ and tissue (Hausenloy and Yellon, 2008). Evidence for the involvement of the autonomic nervous system are derived from studies using ganglion blockers [hexamethonium (Gho et al., 1996; Schoemaker and van Heijningen, 2000; Liem et al., 2002; Wolfrum et al., 2002) and trimetaphan (Loukogeorgakis et al., 2005)] to inhibit the protective effect of RIC. Others have implicated the neuronal pathway by demonstrating the loss of RIC protection in animals subjected to nerve resection (Ding et al., 2001; Dong et al., 2004; Lim et al., 2010) and vagotomy (Brzozowski et al., 2004b). We have recently reported that in the murine model of remote limb preconditioning the neural pathway can be divided into separate components served by the femoral and the sciatic nerves, as resection of either of these nerves alone only partially blocked the protection (Lim et al., 2010).

The current understanding of the neuronal pathway involves the release of endogenous autocoids, including neuropeptides such as CGRP (Tang et al., 1999; Xiao et al., 2001; Brzozowski et al., 2004a), adenosine (Ding et al., 2001; Liem et al., 2002; Dong et al., 2004), and bradykinin (Schoemaker and van Heijningen, 2000), from the remotely conditioned organ or tissue to activate local afferent nerves which then stimulate efferent nerves that terminate at the remote organ and tissue to mediate protection. Numerous studies have further implicated sensory C-fibers as the essential first leg of neurotransmission since RIC-induced protection can be abrogated when subjects were pre-treated with capsaicin to deactivate the afferent sensory nerves (Tang et al., 1999; Xiao et al., 2001; Brzozowski et al., 2004a).

\section{HUMORAL PATHWAY}

A blood-borne factor conveying the cardioprotective signal from the remote organ or tissue has been supported by two main observations: (1) coronary effluent from the ischemic conditioned heart (Dickson et al., 1999a, 2001) or blood from the conditioned animal (Dickson et al., 1999b) can protect a naive recipient heart from IRI, suggesting the transfer of protective humoral factor(s); and (2) a period of reperfusion of the remote conditioned organ was required for protection suggesting that protective stimulus required wash-out of a protective blood-borne humoral factor(s) generated in the conditioned site and transported throughout the circulation (McClanahan et al., 1993; Gho et al., 1996; Weinbrenner et al., 2002).

Activation of adenosine (Pell et al., 1998; Takaoka et al., 1999; Kerendi et al., 2005; Tsubota et al., 2010), bradykinin-2 (Wolfrum et al., 2002), opioids (Dickson et al., 2001, 2002; Patel et al., 2002; Weinbrenner et al., 2004; Zhou et al., 2011), erythropoietin (Diwan et al., 2008a,b), $\mathrm{CB}_{2}$ endocannabinoid (Hajrasouliha et al., 2008), angiotensin-1 (Singh and Chopra, 2004), and prostaglandin (Brzozowski et al., 2004a) receptors and the associated signaling pathways has been implicated in mediating the protective effect of RIC. However, whether they constitute the endogenous substances that are generated in the remote conditioned organ or tissue and being transported to the injured organ target through blood circulation remains unknown. Although the actual identity of circulating humoral factors remains unknown, an elegant study by Shimizu et al. (2009) has identified the cardioprotective humoral factors, generated in response to RIPC of limb, to be hydrophobic and $<15 \mathrm{kDa}$ in size. Serejo et al. (2007) showed that the humoral factors released from the ischemic preconditioned heart were thermolabile, hydrophobic, and $>3.5 \mathrm{kDa}$, which cardioprotect via PKC activation. Similarly, Breivik et al. (2011) reported that coronary IPC effluent contained hydrophobic cytoprotective factors with molecular mass of $<30 \mathrm{kDa}$, which conferred cardioprotection via PI3K/Akt pathway when administered either as a preconditioning or postconditioning mimetic. An early proteomic study of renal RIC in rats did not detect any supported protective factors with molecular mass of $>8 \mathrm{kDa}$ (Lang et al., 2006). Taken together, the humoral factors are likely to be hydrophobic with a 
molecular mass between 3.5 and $8 \mathrm{kDa}$. Why the identification of the humoral factor(s) continues to elude investigators thus far is unclear.

\section{SYSTEMIC RESPONSE}

Remote ischemic conditioning has been shown to provoke a systemic protective response involving modulation of immune cells either at post-translational level or through transcriptional regulation (Saxena et al., 2010). Microarray analysis of blood samples obtained from healthy human volunteers subjected to brief forearm ischemia revealed suppression of proinflammatory genes encoding proteins involve in leukocyte chemotaxis, adhesion, migration, and exocytosis, as well as innate immunity responses, cytokine synthesis, and apoptosis. On the other hand, anti-inflammatory genes such HSP 70 and calpastatin were upregulated (Konstantinov et al., 2004). The changes of this gene expression profile were later found to be correlated with functional changes in human leukocytes, an effect last up to 10 days after RIPC (Shimizu et al., 2010). This finding was in agreement with a previous study reported that RIPC of forearm reduced expression of neutrophil CD11b and platelet-neutrophil complexes in human volunteers (Kharbanda et al., 2001). IPC of liver has also been shown to attenuate increased in P-selectin expression and neutrophil infiltration in multiple remote organs (including lung, stomach, pancreas, small intestine, and colon) through inhibition of systemic TNF $\alpha$ production (Peralta et al., 2001). Subsequent studies in mice also showed upregulation of genes associated with cytoprotection, growth and metabolism, DNA repair, and redox regulation by RIPC of the limb (Konstantinov et al., 2005a) and mesenteric (Huda et al., 2005). Furthermore, Li et al. (2004) demonstrated that delayed RIPC-induced cardioprotection was abrogated in mice with deficient in transcription factor NFкB p105 subunit supporting the important role of gene transcription in mediating the protective effect of RIC.

\section{NOVEL CONCEPTS IN REMOTE ISCHEMIC CONDITIONING DELAYED REMOTE ISCHEMIC PRECONDITIONING}

Similar to IPC, there are two phases of RIPC: early RIPC results in acute protection through post-translational protein modification, and delayed RIPC providing second phase of prolonged protection against ischemic injury (Table 1). An elegant temporal characteristic study by Moses et al. (2005) has demonstrated that the therapeutic time window of delayed RIPC is similar to conventional IPC, i.e., from $24 \mathrm{~h}$ and lasting for up to $72 \mathrm{~h}$. Interestingly, a recent study in rat focal cerebral ischemia has shown that the delayed protection of RIPC can be initiated as early as $12 \mathrm{~h}$ after stimulus, narrowing the gap between the early and delayed protection (Ren et al., 2008). Several studies have implicated iNOS as one of the mechanism underlying the delayed RIPC (Wang et al., 2001; Xiao et al., 2001; Tokuno et al., 2002; Li et al., 2004). Other potential mechanisms include $\alpha$-CGRP (Tang et al., 1999; Xiao et al., 2001; Hu et al., 2002), sarcolemmal $\mathrm{K}_{\text {ATP }}$ channels (Moses et al., 2005), mitochondria $\mathrm{K}_{\mathrm{ATP}}$ channels (Moses et al., 2005; Wu et al., 2011), and antioxidant MnSOD (Yuan et al., 2010; Wu et al., 2011). Using a knock-out model, Schulte et al. (2004) have shown that adenosine $A_{1}$ receptor is essential for the delayed cardioprotection induced by permanent bilateral ligation of the internal carotid arteries. However, this delayed protection may not be considered as a "true" preconditioning because it was not produced by the conventional protocol of brief ischemia and reperfusion.

\section{DELAYED REMOTE ISCHEMIC POSTCONDITIONING}

Previous studies have suggested that reperfusion-induced inflammatory responses occur not only at the early phase of reperfusion, but also extend to prolonged reperfusion (Boyle et al., 1997). Similarly, Zhao et al. (2000, 2001) have demonstrated a progressive increase in the extent of myocardial injury from early $(6 \mathrm{~h})$ to late periods (24-48 h) of reperfusion in canine hearts. These findings suggest that myocardial reperfusion injury may be an ongoing process resulting in a "wavefront of reperfusion injury" thereby providing an extended window for therapeutic intervention. In this regard, Ren et al. (2009) showed that, at least in the brain, the infarct-sparing effect of RIPost was still evident when the application of RIPost was delayed by $3 \mathrm{~h}$, but not $6 \mathrm{~h}$, into reperfusion. Whether it is possible to delay RIC in other organs or tissue remains to be determined.

Table 1 | Experimental studies on delayed remote ischemic preconditioning.

\begin{tabular}{|c|c|c|c|c|c|}
\hline Species & RIPC site & Delayed duration (h) & Site of ischemic insult & Potential mechanisms & Study \\
\hline \multirow[t]{2}{*}{ Mouse } & Hindlimb & 24 & Heart & iNOS, NFKB & Li et al. (2004) \\
\hline & Brain & $24-32$ & & iNOS & Tokuno et al. (2002) \\
\hline \multirow[t]{5}{*}{ Rat } & Hindlimb & 12 and 48 & Brain & - & Ren et al. (2008) \\
\hline & & 24 & & MnSOD, xanthine oxidase & Yuan et al. (2010) \\
\hline & Intestine & 24 & Heart & iNOS & Wang et al. (2001) \\
\hline & & $24-72$ & & iNOS, CGRP & Xiao et al. (2001) \\
\hline & & 24 & & CGRP & Hu et al. (2002) \\
\hline Rabbit & Intestine & 24 & Heart & CGRP & Tang et al. (1999) \\
\hline Pig & Hindlimb & $24-72$ & Latissimus dorsi muscle & $m K_{\text {ATP }}, \mathrm{sK}_{\text {ATP }}$ & Moses et al. (2005) \\
\hline
\end{tabular}




\section{CHRONIC STIMULUS FOR LONG-TERM PROTECTION}

The majority of RIC studies have focused on administering a single RIC stimulus and demonstrating acute protection against IRI (Hausenloy and Yellon, 2008). Intriguingly, a recent experiment study has demonstrated that administering repeated remote limb postconditioning over 2 weeks could prevent adverse LV remodeling in the rat heart following an acute MI (Wei et al., 2011). The cardioprotection afforded by repeated RIC was shown to be associated with reduced myocardial oxidative stress and inflammatory cell infiltration (Wei et al., 2011). This finding is in agreement with the authors' previous study conducted in healthy human volunteers in which RIPC applied daily to the forearm for 10 days negatively affected circulating neutrophil function including reduction in adhesion, exocytosis, phagocytosis, and enhancement in lipopolysaccharide-induced cytokine secretion (Shimizu et al., 2010).

\section{REMOTE PRECONDITIONING OF TRAUMA}

Ren et al. (2004) showed that a single abdominal surgical incision protected the murine heart from subsequent acute IRI in a TNF $\alpha$ independent manner. This study suggested that protection could be elicited by non-ischemic stimulus which they term "remote preconditioning of trauma." A subsequent mechanistic study by the same group has revealed the involvement of neurogenic pathways whereby transverse abdominal incision stimulates peripheral nociception which in turn activate the cardiac sympathetic nerves via spinal nerves and induce cardioprotection through the activation of PKC- $\varepsilon$ and inhibition of PKC- $\delta$ in a bradykinin-dependent manner as well as the activation of the mitochondria $\mathrm{K}_{\mathrm{ATP}}$ channels (Jones et al., 2009). Furthermore, a recent study by Gross et al. (2011) has confirmed this protective phenomenon in a larger animal model (i.e., dog) and has implicated the cytochrome P450 epoxygenase pathway as a mediatory factor. Interesting, remote preconditioning of trauma could be mimicked non-invasively by topical application of capsaicin to directly stimulate the cutaneous sensory C-fibers suggesting a novel clinical application of remote conditioning without ischemia or trauma (Jones et al., 2009).

\section{REMOTE ISCHEMIC CONDITIONING FOR ORGAN TRANSPLANT}

In addition to protecting the host's organs and tissues, RIC has been shown to confer the ability to protect transplanted organs from injury. In a porcine model of orthotopic heart transplantation, Konstantinov et al. (2005b) demonstrated that four $5 \mathrm{~min}$ cycles of RIPC applied on the recipient's limb can protect the denervated donor heart from acute IRI. On the other hand, RIPC applied on the donor's limb significantly reduced myocardial injury in explanted donor heart subjected to ex vivo IRI on a Langendorff preparation (Kristiansen et al., 2005). This finding suggested that the protective information is remembered within the explanted heart without the need of ongoing stimulation. Both studies also showed that the protection conferred by RIPC was abolished by glibenclamide suggesting a $\mathrm{K}_{\mathrm{ATP}}$ channel-depending mechanism (Konstantinov et al., 2005b; Kristiansen et al., 2005). Using specific blockers of $\mathrm{K}_{\mathrm{ATP}}$ channels given before myocardial IRI and after the heart had been explanted, Kristiansen et al. (2005) further identified activation of mitochondrial $K_{\mathrm{ATP}}$, but not sarcolemmal $\mathrm{K}_{\mathrm{ATP}}$, channel as the main end effector of RIPC in the protected organ. These early studies have indicated RIC as a potential protective strategy for future organ transplantation in human.

\section{MOBILIZATION OF ENDOGENOUS STEM AND PROGENITOR CELLS}

Recent advances in cell biology have identified endogenous stem and progenitor cells as part of innate reparatory components after organ or tissue injury. Endogenous stem and progenitor cells can be mobilized to target tissues and serve as integrated participants in regenerating the injured organ or tissues and/or as supportive players via pleiotropic paracrine effects (Chen et al., 2011; Krankel et al., 2011). An early study by Ii et al. (2005) demonstrated the ability of IPC to recruit endogenous endothelial progenitor cells to the infarcted myocardium in a NOS-dependent manner and this effect was associated with infarct size reduction, increased angiogenesis, and improvement of cardiac function. The mobilizing and homing effect of IPC was subsequently illustrated on other cell types including mesenchymal and hematopoietic stem cells in a porcine model of acute myocardial IRI (Gyongyosi et al., 2010). In the setting of RIPC, Kamota et al. (2009) showed that intermittent abdominal aorta occlusion increased the accumulation of bone marrow-derived sca- ${ }^{+}$and c-kit ${ }^{+}$stem cells in infarcted hearts through a SDF-1/CXCR4-dependent mechanism. These encouraging findings may have a positive impact on future clinical translation of RIC.

\section{CLINICAL APPLICATION}

The ability to recapitulate RIC protection using the upper or lower limb has greatly facilitated the translation of RIC into the clinical setting of acute IRI. Preliminary clinical studies by MacAllister's group (Kharbanda et al., 2002) first demonstrated that RIC could be non-invasively reproduced in human volunteers using a standard blood pressure cuff to induce brief cycles of non-lethal ischemia and reperfusion in the arm. Since then, a number of clinical studies have investigated RIC in different clinical settings of acute IRI.

\section{PROTECTING THE HEART USING RIC}

The majority of the clinical RIC studies have been designed to investigate whether the heart can be protected against acute IRI in a variety of clinical settings including cardiac surgery, during percutaneous coronary intervention (PCI), and in an acute MI. In 2006, the first clinical proof-of-concept clinical study to demonstrate that RIC may be beneficial in the clinical setting was conducted in children undergoing corrective cardiac surgery for congenital heart disease (Cheung et al., 2006), an operation which is normally associated with significant morbidity and mortality due to inadequate cardioprotection during surgery. In that study, Cheung et al. (2006) reported that RIC (four 5 min cuff inflations and deflations of a cuff placed on the thigh to $15 \mathrm{mmHg}$ above systolic blood pressure) administered prior to cardiac surgery reduced peri-operative myocardial injury (less troponin I release), lowered inotrope requirements and reduced airway pressures. A year later, we demonstrated that (three $5 \mathrm{~min}$ cuff inflations and deflations of a cuff placed on the upper arm to $200 \mathrm{mmHg}$ ) administered prior to cardiac surgery reduced peri-operative myocardial injury (43\% less troponin T release) in adult patients undergoing elective CABG surgery (Hausenloy et al., 2007). 
Since the publication of these clinical studies there have been both positive (Venugopal et al., 2009; Li et al., 2010; Thielmann et al., 2010; Choi et al., 2011) and negative (Rahman et al., 2010; Karuppasamy et al., 2011) studies with RIC in this clinical setting. The reasons for these divergent findings are not clear but may be attributable to a number of different factors including: (1) the use of concomitant medication such as inhaled anesthetics (for example isoflurane), intravenous anesthetics such as propofol, and intravenous nitrates all of which may cardioprotect during CABG surgery; (2) the timing of the RIC stimulus which was prior to cardiac surgery in the positive studies and was after surgical incision in one of the negative studies (Rahman et al., 2010); (3) the patient population and type of cardiac surgery. Whether RIC is actually beneficial in the clinical setting of CABG surgery should become clearer with the completion of two large multi-center randomized controlled clinical trials in the UK (the ERICCA trial; Hausenloy et al., 2011) and Germany (the RIPHeart trial; http://clinicaltrials.gov/ct2/show/NCT01067703). RIC has also been reported to protect the heart in a number of different clinical settings of acute IRI including abdominal aortic aneurysm surgery (Ali et al., 2007), elective PCI (Hoole et al., 2009), and ST-elevation MI (Botker et al., 2010; Munk et al., 2010; Rentoukas et al., 2010). However, further study is required to characterize the most effective RIC stimulus in these different clinical settings.

\section{PROTECTING OTHER ORGANS AND TISSUE USING RIC}

Remote ischemic conditioning using the upper to lower limb has the potential to be beneficial in other organs and tissue such as the kidney, brain, liver, lung, and so on. Acute kidney injury following CABG or major vascular surgery is associated with worse clinical outcomes. Preliminary clinical studies have reported beneficial effects of RIC in these settings in terms of reduced incidence of acute kidney injury (Ali et al., 2007; Venugopal et al., 2010), although not all studies have been positive (Rahman et al., 2010; Choi et al., 2011). Recent clinical studies have implicated remote limb preconditioning to be safe and well tolerated in patients with aneurysmal subarachnoid hemorrhage (Koch et al., 2011) and carotid endarterectomy (Walsh

\section{REFERENCES}

Abu-Amara, M., Yang, S. Y., Quaglia, A., Rowley, P., De Mel, A., Tapuria, N., Seifalian, A., Davidson, B., and Fuller, B. (2011a). Nitric oxide is an essential mediator of the protective effects of remote ischaemic preconditioning in a mouse model of liver ischaemia/reperfusion injury. Clin. Sci. 121, 257-266.

Abu-Amara, M., Yang, S. Y., Quaglia, A., Rowley, P., Fuller, B., Seifalian, A., and Davidson, B. (2011b). Role of endothelial nitric oxide synthase in remote ischemic preconditioning of the mouse liver. Liver Transpl. 17, 610-619.

Addison, P. D., Neligan, P. C., Ashrafpour, H., Khan, A., Zhong, A., Moses, M., Forrest, C. R., and Pang,
C. Y. (2003). Noninvasive remote ischemic preconditioning for global protection of skeletal muscle against infarction. Am. J. Physiol. Heart Circ. Physiol. 285, H1435-H1443.

Ali, Z. A., Callaghan, C. J., Lim, E., Ali, A. A., Nouraei, S. A., Akthar, A. M., Boyle, J. R., Varty, K., Kharbanda, R. K., Dutka, D. P., and Gaunt, M. E. (2007). Remote ischemic preconditioning reduces myocardial and renal injury after elective abdominal aortic aneurysm repair: a randomized controlled trial. Circulation 116, I98-I105.

Ates, E., Genc, E., Erkasap, N., Erkasap, S., Akman, S., Firat, P., Emre, S., and Kiper, H. (2002). Renal protection by brief liver ischemia in rats. Transplantation 74, 1247-1251.

et al., 2010), supporting the aforementioned encouraging animal data and future clinical trials. The REPAIR trial is currently investigating whether RIC can improve graft renal function in patients undergoing live donor-related renal transplantation. Clinical studies are required to investigate whether RIC can protect the brain, liver, and other organs against acute IRI. Successful results from experimental studies raise the possibility of applying RIC in elective reconstructive and flap microsurgery such as adipose tissue grafting to the post-mastectomy patient, autologous muscle transplantation for wound coverage, skin grafting for burn victim, and reattachment of finger or other body parts.

\section{CONCLUSION}

The discovery of RIC has provided an innovative therapeutic strategy for the prevention of acute IRI in susceptible organs and tissues. The ability to induce RIC using a standard blood pressure cuff placed on the upper or lower limb has facilitated its translation into the clinical setting. RIC is simple to apply, non-invasive and virtually cost-free, and a single RIC stimulus offers multiorgan protection, lending itself to a variety of clinical settings in which there is organ or tissue acute IRI. The promising results obtained from several proof-of-concept clinical studies (mainly in the heart) have encouraged further laboratory investigation into the complex mechanisms underlying its protective effect. A better understanding of the complex signaling events involved in transduction of the RIC signal from the remote organ and tissue to the protected target may allow the imminent discovery of novel pharmacological agents to directly activate the protective signaling pathways. For now large multi-center clinical trials are underway to investigate whether RIC can actually improve clinical outcomes in patients with CHD.

\section{ACKNOWLEDGMENTS}

This work was supported by the British Heart Foundation grant number FS/10/039/28270. This work was undertaken at UCLH/UCL who received a proportion of funding from the Department of Health's NIHR Biomedical Research Centres funding scheme.

Birnbaum, Y., Hale, S. L., and Kloner, R. A. (1997). Ischemic preconditioning at a distance: reduction of myocardial infarct size by partial reduction of blood supply combined with rapid stimulation of the gastrocnemius muscle in the rabbit. Circulation 96, 1641-1646.

Botker, H. E., Kharbanda, R., Schmidt, M. R., Bottcher, M., Kaltoft, A. K., Terkelsen, C. J., Munk, K., Andersen, N. H., Hansen, T. M., Trautner, S., Lassen, J. F., Christiansen, E. H., Krusell, L. R., Kristensen, S. D. Thuesen, L., Nielsen, S. S., Rehling, M., Sorensen, H. T., Redington, A. N., and Nielsen, T. T. (2010). Remote ischaemic conditioning before hospital admission, as a complement to angioplasty, and effect on myocardial salvage in patients with acute myocardial infarction: a randomised trial. Lancet 375, 727-734.

Boyle, E. M., Pohlman, T. H., Johnson, M. C., and Verrier, E. D. (1997) Endothelial cell injury in cardiovascular surgery: the systemic inflammatory response. Ann. Thorac. Surg. 63, 277-277.

Breivik, L., Helgeland, E., Aarnes, E. K., Mrdalj, J., and Jonassen, A. K. (2011). Remote postconditioning by humoral factors in effluent from ischemic preconditioned rat hearts is mediated via PI3K/Aktdependent cell-survival signaling at reperfusion. Basic Res. Cardiol. 106, 135-145. 
Brzozowski, T., Konturek, P. C., Konturek, S. J., Pajdo, R., Kwiecien, S., Pawlik, M., Drozdowicz, D., Sliwowski, Z., and Pawlik, W. W. (2004a). Ischemic preconditioning of remote organs attenuates gastric ischemia-reperfusion injury through involvement of prostaglandins and sensory nerves. Eur. J. Pharmacol. 499, 201-213.

Brzozowski, T., Konturek, P. C., Pajdo, R., Kwiecien, S., Sliwowski, Z., Drozdowicz, D., Ptak-Belowska, A., Pawlik, M., Konturek, S. J., Pawlik, W. W., and Hahn, G. G. (2004b). Importance of brain-gut axis in the gastroprotection induced by gastric and remote preconditioning. J. Physiol. Pharmacol. 55, 165-177.

Candilio, L., Hausenloy, D. J., and Yellon, D. M. (2011). Remote ischemic conditioning: a clinical trial's update. J. Cardiovasc. Pharmacol. Ther. 16, 304-312.

Chen, F. M., Wu, L. A., Zhang, M., Zhang, R., and Sun, H. H. (2011). Homing of endogenous stem/progenitor cells for in situ tissue regeneration: promises, strategies, and translational perspectives. Biomaterials 32, 3189-3209.

Cheung, M. M., Kharbanda, R. K., Konstantinov, I. E., Shimizu, M., Frndova, H., Li, J., Holtby, H. M., Cox, P. N., Smallhorn, J. F., Van Arsdell, G. S., and Redington, A. N. (2006). Randomized controlled trial of the effects of remote ischemic preconditioning on children undergoing cardiac surgery: first clinical application in humans. J. Am. Coll. Cardiol. 47, 2277-2282.

Choi, Y. S., Shim, J. K., Kim, J. C., Kang, K. S., Seo, Y. H., Ahn, K. R., and Kwak, Y. L. (2011). Effect of remote ischemic preconditioning on renal dysfunction after complex valvular heart surgery: a randomized controlled trial. J. Thorac. Cardiovasc. Surg. 142, 148-154.

de Zeeuw, S., Lameris, T. W., Duncker, D. J., Hasan, D., Boomsma, F., Van Den Meiracker, A. H., and Verdouw, P. D. (2001). Cardioprotection in pigs by exogenous norepinephrine but not by cerebral ischemia-induced release of endogenous norepinephrine. Stroke 32, 767-774.

Dickson, E. W., Blehar, D. J., Carraway, R. E., Heard, S. O., Steinberg, G., and Przyklenk, K. (2001). Naloxone blocks transferred preconditioning in isolated rabbit hearts. J. Mol. Cell. Cardiol. 33, 1751-1756.

Dickson, E. W., Lorbar, M., Porcaro, W. A., Fenton, R. A., Reinhardt, C. P., Gysembergh, A., and Przyklenk, K. (1999a). Rabbit heart can be "preconditioned" via transfer of coronary effluent. Am. J. Physiol. 277, H2451-H2457.

Dickson, E. W., Reinhardt, C. P., Renzi, F. P., Becker, R. C., Porcaro, W. A., and Heard, S. O. (1999b). Ischemic preconditioning may be transferable via whole blood transfusion: preliminary evidence. J. Thromb. Thrombolysis 8, 123-129.

Dickson, E. W., Tubbs, R. J., Porcaro, W. A., Lee, W. J., Blehar, D. J., Carraway, R. E., Darling, C. E., and Przyklenk, K. (2002). Myocardial preconditioning factors evoke mesenteric ischemic tolerance via opioid receptors and K(ATP) channels. Am. J. Physiol. Heart Circ. Physiol. 283, $\mathrm{H} 22-\mathrm{H} 28$.

Ding, Y. F., Zhang, M. M., and He, R. R. (2001). Role of renal nerve in cardioprotection provided by renal ischemic preconditioning in anesthetized rabbits. Sheng Li Xue Bao 53, 7-12.

Diwan, V., Jaggi, A. S., Singh, M., Singh, N., and Singh, D. (2008a). Possible involvement of erythropoietin in remote renal preconditioninginduced cardioprotection in rats. $J$. Cardiovasc. Pharmacol. 51, 126-130.

Diwan, V., Kant, R., Jaggi, A. S., Singh, N., and Singh, D. (2008b). Signal mechanism activated by erythropoietin preconditioning and remote renal preconditioning-induced cardioprotection. Mol. Cell. Biochem. 315, 195-201.

Dong, J. H., Liu, Y. X., Ji, E. S., and He, R. R. (2004). Limb ischemic preconditioning reduces infarct size following myocardial ischemia-reperfusion in rats. Sheng Li Xue Bao 56, 41-46.

Eberlin, K. R., McCormack, M. C., Nguyen, J. T., Tatlidede, H. S., Randolph, M. A., and Austen, W. G. Jr. (2009). Sequential limb ischemia demonstrates remote postconditioning protection of murine skeletal muscle. Plast. Reconstr. Surg. 123, 8S-16S.

Fernandez, L., Heredia, N., Grande, L., Gomez, G., Rimola, A., Marco, A., Gelpi, E., Rosello-Catafau, J., and Peralta, C. (2002). Preconditioning protects liver and lung damage in rat liver transplantation: role of xanthine/xanthine oxidase. Hepatology 36, 562-572.

Gho, B. C., Schoemaker, R. G., Van Den Doel, M. A., Duncker, D. J., and Verdouw, P. D. (1996). Myocardial protection by brief ischemia in noncardiac tissue. Circulation 94, 2193-2200.

Gross, G. J., Baker, J. E., Moore, J., Falck, J. R., and Nithipatikom, K. (2011). Abdominal surgical incision induces remote preconditioning of trauma (RPCT) via activation of bradykinin receptors (BK2R) and the cytochrome $\mathrm{P} 450$ epoxygenase pathway in canine hearts. Cardiovasc. Drugs Ther. 25, 517-522.

Gyongyosi, M., Posa, A., Pavo, N., Hemetsberger, R., Kvakan, H., Steiner-Boker, S., Petrasi, Z., Manczur, F., Pavo, I. J., Edes, I. F., Wojta, J., Glogar, D., and Huber, K. (2010). Differential effect of ischaemic preconditioning on mobilisation and recruitment of haematopoietic and mesenchymal stem cells in porcine myocardial ischaemia-reperfusion. Thromb. Haemost. 104, 376-384.

Hajrasouliha, A. R., Tavakoli, S., Ghasemi, M., Jabehdar-Maralani, P., Sadeghipour, H., Ebrahimi, F., and Dehpour, A. R. (2008). Endogenous cannabinoids contribute to remote ischemic preconditioning via cannabinoid CB2 receptors in the rat heart. Eur. J. Pharmacol. 579, 246-252.

Hausenloy, D. J., Candilio, L., Laing, C., Kunst, G., Pepper, J., Kolvekar, S., Evans, R., Robertson, S., Knight R., Ariti, C., Clayton, T., and Yellon, D. M. (2011). Effect of remote ischemic preconditioning on clinical outcomes in patients undergoing coronary artery bypass graft surgery (ERICCA): rationale and study design of a multi-centre randomized double-blinded controlled clinical trial. Clin. Res. Cardiol. PMID: 22186969. [Epub ahead of print].

Hausenloy, D. J., Mwamure, P. K., Venugopal, V., Harris, J., Barnard, M. Grundy, E., Ashley, E., Vichare, S., Di Salvo, C., Kolvekar, S., Hayward, M., Keogh, B., MacAllister, R. J., and Yellon, D. M. (2007). Effect of remote ischaemic preconditioning on myocardial injury in patients undergoing coronary artery bypass graft surgery: a randomised controlled trial. Lancet 370, 575-579.

Hausenloy, D. J., and Yellon, D. M. (2008). Remote ischaemic preconditioning: underlying mechanisms and clinical application. Cardiovasc. Res. 79, 377-386.

Heidbreder, M., Naumann, A., Tempel, K., Dominiak, P., and Dendorfer, A. (2008). Remote vs. ischaemic preconditioning: the differential role of mitogen-activated protein kinase pathways. Cardiovasc. Res. 78, 108-115.

Heusch, G., Musiolik, J., Kottenberg, E. Peters, J., Jakob, H., and Thielmann, M. (2012). STAT5 activation and cardioprotection by remote ischemic preconditioning in humans. Circ. Res. 110, 111-115.

Holzner, P. A., Kulemann, B., Kuesters, S., Timme, S., Hoeppner, J., Hopt, U. T., and Marjanovic, G. (2011). Impact of remote ischemic preconditioning on wound healing in small bowel anastomoses. World J. Gastroenterol. 17, 1308-1316.

Hoole, S. P., Heck, P. M., Sharples, L., Khan, S. N., Duehmke, R., Densem, C. G., Clarke, S. C., Shapiro, L. M., Schofield, P. M., O'Sullivan, M., and Dutka, D. P. (2009). Cardiac Remote Ischemic Preconditioning in Coronary Stenting (CRISP Stent) Study: a prospective, randomized control trial. Circulation 119, 820-827.

Hu, C. P., Peng, J., Xiao, L., Ye, F., Deng, H. W., and Li, Y. J. (2002). Effect of age on alpha-calcitonin gene-related peptide-mediated delayed cardioprotection induced by intestinal preconditioning in rats. Regul. Pept. 107, 137-143.

Huda, R., Chung, D. H., and Mathru, M. (2005). Ischemic preconditioning at a distance: altered gene expression in mouse heart and other organs following brief occlusion of the mesenteric artery. Heart Lung Circ. 14, 36-43.

Ii, M., Nishimura, H., Iwakura, A., Wecker, A., Eaton, E., Asahara, T., and Losordo, D. W. (2005). Endothelial progenitor cells are rapidly recruited to myocardium and mediate protective effect of ischemic preconditioning via "imported" nitric oxide synthase activity. Circulation 111, 1114-1120.

Jan, W. C., Chen, C. H., Tsai, P. S., and Huang, C. J. (2011). Limb ischemic preconditioning mitigates lung injury induced by haemorrhagic shock/resuscitation in rats. Resuscitation 82, 760-766.

Jensen, H. A., Loukogeorgakis, S., Yannopoulos, F., Rimpilainen, E. Petzold, A., Tuominen, H., Lepola, P., MacAllister, R. J., Deanfield, J. E., Makela, T., Alestalo, K., Kiviluoma, K., Anttila, V., Tsang, V., and Juvonen, T. (2011). Remote ischemic preconditioning protects the brain against injury after hypothermic circulatory arrest. Circulation 123, 714-721.

Jones, W. K., Fan, G. C., Liao, S., Zhang, J. M., Wang, Y., Weintraub, N. L., Kranias, E. G., Schultz, J. E., Lorenz, J., and Ren, X. (2009). Peripheral nociception associated with surgical incision elicits remote nonischemic cardioprotection via neurogenic activation of protein kinase $\mathrm{C}$ signaling. Circulation 120, S1-S9.

Kamota, T., Li, T. S., Morikage, N., Murakami, M., Ohshima, M., 
Kubo, M., Kobayashi, T., Mikamo, A., Ikeda, Y., Matsuzaki, M., and Hamano, K. (2009). Ischemic preconditioning enhances the mobilization and recruitment of bone marrow stem cells to protect against ischemia/reperfusion injury in the late phase. J. Am. Coll. Cardiol. 53, 1814-1822.

Kanoria, S., Jalan, R., Davies, N. A., Seifalian, A. M., Williams, R., and Davidson, B. R. (2006). Remote ischaemic preconditioning of the hind limb reduces experimental liver warm ischaemia-reperfusion injury. Br. J. Surg. 93, 762-768.

Kanoria, S., Jalan, R., Seifalian, A. M., Williams, R., and Davidson, B. R. (2007). Protocols and mechanisms for remote ischemic preconditioning: a novel method for reducing ischemia reperfusion injury. Transplantation 84, 445-458.

Kant, R., Diwan, V., Jaggi, A. S., Singh, N., and Singh, D. (2008). Remote renal preconditioning-induced cardioprotection: a key role of hypoxia inducible factor-prolyl 4-hydroxylases. Mol. Cell. Biochem. 312, 25-31.

Karuppasamy, P., Chaubey, S., Dew, T., Musto, R., Sherwood, R., Desai, J., John, L., Shah, A. M., Marber, M. S., and Kunst, G. (2011). Remote intermittent ischemia before coronary artery bypass graft surgery: a strategy to reduce injury and inflammation? Basic Res. Cardiol. 106, 511-519.

Kerendi, F., Kin, H., Halkos, M. E., Jiang, R., Zatta, A. J., Zhao, Z. Q., Guyton, R. A., and Vinten-Johansen, J. (2005). Remote postconditioning. Brief renal ischemia and reperfusion applied before coronary artery reperfusion reduces myocardial infarct size via endogenous activation of adenosine receptors. Basic Res. Cardiol. 100, 404-412.

Kharbanda, R. K., Mortensen, U. M., White, P. A., Kristiansen, S. B., Schmidt, M. R., Hoschtitzky, J. A., Vogel, M., Sorensen, K., Redington, A. N., and MacAllister, R. (2002). Transient limb ischemia induces remote ischemic preconditioning in vivo. Circulation 106, 2881-2883.

Kharbanda, R. K., Peters, M., Walton, B., Kattenhorn, M., Mullen, M., Klein, N., Vallance, P., Deanfield, J., and MacAllister, R. (2001). Ischemic preconditioning prevents endothelial injury and systemic neutrophil activation during ischemia-reperfusion in humans in vivo. Circulation 103, 1624-1630.

Koch, S., Katsnelson, M., Dong, C., and Perez-Pinzon, M. (2011). Remote ischemic limb preconditioning after subarachnoid hemorrhage: a phase Ib study of safety and feasibility. Stroke 42, 1387-1391.

Konstantinov, I. E., Arab, S., Kharbanda, R. K., Li, J., Cheung, M. M., Cherepanov, V., Downey, G. P., Liu, P. P., Cukerman, E., Coles, J. G., and Redington, A. N. (2004). The remote ischemic preconditioning stimulus modifies inflammatory gene expression in humans. Physiol. Genomics 19, 143-150.

Konstantinov, I. E., Arab, S., Li, J., Coles, J. G., Boscarino, C., Mori, A., Cukerman, E., Dawood, F., Cheung, M. M., Shimizu, M., Liu, P. P., and Redington, A. N. (2005a). The remote ischemic preconditioning stimulus modifies gene expression in mouse myocardium. J. Thorac. Cardiovasc. Surg. 130, 1326-1332.

Konstantinov, I. E., Li, J., Cheung, M. M., Shimizu, M., Stokoe, J., Kharbanda, R. K., and Redington, A. N. (2005b). Remote ischemic preconditioning of the recipient reduces myocardial ischemia-reperfusion injury of the denervated donor heart via a Katp channel-dependent mechanism. Transplantation 79, 1691-1695.

Krankel, N., Spinetti, G., Amadesi, S., and Madeddu, P. (2011). Targeting stem cell niches and trafficking for cardiovascular therapy. Pharmacol. Ther. 129, 62-81.

Kristiansen, S. B., Henning, O., Kharbanda, R. K., Nielsen-Kudsk, J. E., Schmidt, M. R., Redington, A. N., Nielsen, T. T., and Botker, H. E. (2005). Remote preconditioning reduces ischemic injury in the explanted heart by a KATP channeldependent mechanism. Am. J. Physiol. Heart Circ. Physiol. 288, H1252H1256.

Kuntscher, M. V., Juran, S., Altmann, J., Menke, H., Gebhard, M. M., and Germann, G. (2003a). Role of nitric oxide in the mechanism of preclamping and remote ischemic preconditioning of adipocutaneous flaps in a rat model. J. Reconstr. Microsurg. 19, 55-60.

Kuntscher, M. V., Kastell, T., Engel, H., Gebhard, M. M., Heitmann, C., and Germann, G. (2003b). Late remote ischemic preconditioning in rat muscle and adipocutaneous flap models. Ann. Plast. Surg. 51, 84-90.

Kuntscher, M. V., Kastell, T., Sauerbier, M., Nobiling, R., Gebhard, M. M., and Germann, G. (2002). Acute remote ischemic preconditioning on a rat cremasteric muscle flap model. Microsurgery 22, 221-226.

Lai, I. R., Chang, K. J., Chen, C. F., and Tsai, H. W. (2006).
Transient limb ischemia induces remote preconditioning in liver among rats: the protective role of heme oxygenase-1. Transplantation 81, 1311-1317.

Lang, S. C., Elsasser, A., Scheler, C., Vetter, S., Tiefenbacher, C. P., Kubler, W., Katus, H. A., and Vogt, A. M. (2006). Myocardial preconditioning and remote renal preconditioning identifying a protective factor using proteomic methods? Basic Res. Cardiol. 101, 149-158.

Lazaris, A. M., Maheras, A. N. Vasdekis, S. N., Karkaletsis, K. G., Charalambopoulos, A., Kakisis, J. D., Martikos, G., Patapis, P., Giamarellos-Bourboulis, E. J., Karatzas, G. M., and Liakakos, T. D. (2009). Protective effect of remote ischemic preconditioning in renal ischemia/reperfusion injury, in a model of thoracoabdominal aorta approach. J. Surg. Res. 154, 267-273.

Li, G., Labruto, F., Sirsjo, A., Chen, F., Vaage, J., and Valen, G. (2004). Myocardial protection by remote preconditioning: the role of nuclear factor kappa-B p105 and inducible nitric oxide synthase. Eur. J. Cardiothorac. Surg. 26, 968-973.

Li, L., Luo, W., Huang, L., Zhang, W., Gao, Y., Jiang, H., Zhang, C., Long, L., and Chen, S. (2010). Remote perconditioning reduces myocardial injury in adult valve replacement: a randomized controlled trial. J. Surg. Res. 164, e21-e26.

Liem, D. A., Verdouw, P. D., Ploeg, H., Kazim, S., and Duncker, D. J. (2002). Sites of action of adenosine in interorgan preconditioning of the heart. Am. J. Physiol. Heart Circ. Physiol. 283, H29-H37.

Lim, S. Y., Yellon, D. M., and Hausenloy, D. J. (2010). The neural and humoral pathways in remote limb ischemic preconditioning. Basic Res. Cardiol. 105, 651-655.

Lloyd-Jones, D., Adams, R., Carnethon, M., De Simone, G., Ferguson, T. B., Flegal, K., Ford, E., Furie, K., Go, A., Greenlund, K., Haase, N., Hailpern, S., Ho, M., Howard, V., Kissela, B., Kittner, S., Lackland, D., Lisabeth, L., Marelli, A., McDermott, M., Meigs, J., Mozaffarian, D., Nichol, G., O’Donnell, C., Roger, V., Rosamond, W., Sacco, R., Sorlie, P., Stafford, R., Steinberger, J., Thom, T., Wasserthiel-Smoller, S., Wong, N., Wylie-Rosett, J., and Hong, Y. (2009). Heart disease and stroke statistics - 2009 update: a report from the American Heart Association Statistics Committee and Stroke Statistics Subcommittee. Circulation 119, e21-e181.
Lotz, C., Lazariotto, M., Redel, A., Smul, T. M., Stumpner, J., Blomeyer, C. Tischer-Zeitz, T., Schmidt, J., Pociej, J., Roewer, N., Kehl, F., and Lange, M. (2011). Activation of peroxisomeproliferator-activated receptors alpha and gamma mediates remote ischemic preconditioning against myocardial infarction in vivo. Exp. Biol. Med. (Maywood) 236, 113-122. Loukogeorgakis, S. P., Panagiotidou, A. T., Broadhead, M. W., Donald, A. Deanfield, J. E., and MacAllister, R. J. (2005). Remote ischemic preconditioning provides early and late protection against endothelial ischemiareperfusion injury in humans: role of the autonomic nervous system. $J$. Am. Coll. Cardiol. 46, 450-456.

McClanahan, T. B., Nao, B. S., Wolke, L. J., Martin, B. J., Mertz, T. E., and Gallagher, K. P. (1993). Brief renal occlusion and reperfusion reduces myocardial infarct size in rabbits. FASEB J. 7, A118.

Moses, M. A., Addison, P. D., Neligan, P. C., Ashrafpour, H., Huang, N., McAllister, S. E., Lipa, J. E., Forrest, C. R., and Pang, C. Y. (2005). Inducing late phase of infarct protection in skeletal muscle by remote preconditioning: efficacy and mechanism. Am. J. Physiol. Regul. Integr. Comp. Physiol. 289, R1609-R1617.

Munk, K., Andersen, N. H., Schmidt, M. R., Nielsen, S. S., Terkelsen, C. J., Sloth, E., Botker, H. E., Nielsen, T. T., and Poulsen, S. H. (2010). Remote ischemic conditioning in patients with myocardial infarction treated with primary angioplasty: impact on left ventricular function assessed by comprehensive echocardiography and gated single-photon emission CT. Circ. Cardiovasc. Imaging 3, 656-662.

Murry, C. E., Jennings, R. B., and Reimer, K. A. (1986). Preconditioning with ischemia: a delay of lethal cell injury in ischemic myocardium. Circulation 74, 1124-1136.

Oxman, T., Arad, M., Klein, R., Avazov, N., and Rabinowitz, B. (1997). Limb ischemia preconditions the heart against reperfusion tachyarrhythmia. Am. J. Physiol. 273, H1707H1712.

Patel, H. H., Moore, J., Hsu, A. K., and Gross, G. J. (2002). Cardioprotection at a distance: mesenteric artery occlusion protects the myocardium via an opioid sensitive mechanism. J. Mol. Cell. Cardiol. 34, 1317-1323.

Pell, T. J., Baxter, G. F., Yellon, D. M., and Drew, G. M. (1998). Renal ischemia preconditions myocardium: role of adenosine receptors and 
ATP-sensitive potassium channels. Am. J. Physiol. 275, H1542-H1547.

Peralta, C., Fernandez, L., Panes, J., Prats, N., Sans, M., Pique, J. M., Gelpi, E., and Rosello-Catafau, J. (2001). Preconditioning protects against systemic disorders associated with hepatic ischemia-reperfusion through blockade of tumor necrosis factor-induced P-selectin upregulation in the rat. Hepatology 33, 100-113.

Przyklenk, K., Bauer, B., Ovize, M., Kloner, R. A., and Whittaker, P. (1993). Regional ischemic "preconditioning" protects remote virgin myocardium from subsequent sustained coronary occlusion. Circulation 87, 893-899.

Rahman, I. A., Mascaro, J. G., Steeds, R. P., Frenneaux, M. P., Nightingale, P., Gosling, P., Townsend, P., Townend, J. N., Green, D., and Bonser, R. S. (2010). Remote ischemic preconditioning in human coronary artery bypass surgery: from promise to disappointment? Circulation 122, S53S59.

Ren, C., Gao, X., Steinberg, G. K., and Zhao, H. (2008). Limb remotepreconditioning protects against focal ischemia in rats and contradicts the dogma of therapeutic time windows for preconditioning. $\mathrm{Neu}$ roscience 151, 1099-1103.

Ren, C., Yan, Z., Wei, D., Gao, X., Chen, X., and Zhao, H. (2009). Limb remote ischemic postconditioning protects against focal ischemia in rats. Brain Res. 1288, 88-94.

Ren, X., Wang, Y., and Jones, W. K. (2004). TNF-alpha is required for late ischemic preconditioning but not for remote preconditioning of trauma. J. Surg. Res. 121, 120-129.

Rentoukas, I., Giannopoulos, G., Kaoukis, A., Kossyvakis, C., Raisakis, K., Driva, M., Panagopoulou, V., Tsarouchas, K., Vavetsi, S., Pyrgakis, V., and Deftereos, S. (2010). Cardioprotective role of remote ischemic periconditioning in primary percutaneous coronary intervention: enhancement by opioid action. JACC Cardiovasc. Interv. 3, 49-55.

Saxena, P., Newman, M. A., Shehatha, J. S., Redington, A. N., and Konstantinov, I. E. (2010). Remote ischemic conditioning: evolution of the concept, mechanisms, and clinical application. J. Card. Surg. 25, 127-134.

Schmidt, M. R., Smerup, M., Konstantinov, I. E., Shimizu, M., Li, J., Cheung, M., White, P. A., Kristiansen, S. B., Sorensen, K., Dzavik, V., Redington, A. N., and Kharbanda, R. K. (2007). Intermittent peripheral tissue ischemia during coronary ischemia reduces myocardial infarction through a KATPdependent mechanism: first demonstration of remote ischemic perconditioning. Am. J. Physiol. Heart Circ. Physiol. 292, H1883-H1890.

Schoemaker, R. G., and van Heijningen, C. L. (2000). Bradykinin mediates cardiac preconditioning at a distance. Am. J. Physiol. Heart Circ. Physiol. 278, H1571-H1576.

Schulte, G., Sommerschild, H., Yang, J., Tokuno, S., Goiny, M., Lovdahl, C., Johansson, B., Fredholm, B. B., and Valen, G. (2004). Adenosine A receptors are necessary for protection of the murine heart by remote, delayed adaptation to ischaemia. Acta Physiol. Scand. 182, 133-143.

Serejo, F. C., Rodrigues, L. F. Jr., Da Silva Tavares, K. C., De Carvalho, A. C., and Nascimento, J. H. (2007). Cardioprotective properties of humoral factors released from rat hearts subject to ischemic preconditioning. J. Cardiovasc. Pharmacol. 49, 214-220.

Shimizu, M., Saxena, P., Konstantinov, I. E., Cherepanov, V., Cheung, M. M., Wearden, P., Zhangdong, H., Schmidt, M., Downey, G. P., and Redington, A. N. (2010). Remote ischemic preconditioning decreases adhesion and selectively modifies functional responses of human neutrophils. J. Surg. Res. 158, 155-161.

Shimizu, M., Tropak, M., Diaz, R. J., Suto, F., Surendra, H., Kuzmin, E., Li, J., Gross, G., Wilson, G. J., Callahan, J., and Redington, A. N. (2009). Transient limb ischaemia remotely preconditions through a humoral mechanism acting directly on the myocardium: evidence suggesting cross-species protection. Clin. Sci. (Lond.) 117, 191-200.

Singh, D., and Chopra, K. (2004). Evidence of the role of angiotensin $\mathrm{AT}(1)$ receptors in remote renal preconditioning of myocardium. Methods Find. Exp. Clin. Pharmacol. 26, 117-122.

Takaoka, A., Nakae, I., Mitsunami, K., Yabe, T., Morikawa, S., Inubushi, T., and Kinoshita, M. (1999). Renal ischemia/reperfusion remotely improves myocardial energy metabolism during myocardial ischemia via adenosine receptors in rabbits: effects of "remote preconditioning". J. Am. Coll. Cardiol. 33, 556-564.

Tanaka, M., Fujiwara, H., Yamasaki, K., Yokota, R., Doyama, K., Inada, T., Ohtani, S., Fujiwara, T., and Sasayama, S. (1998). Expression of heat shock protein after ischemic preconditioning in rabbit hearts. Jpn. Circ. J. 62, 512-516.
Tang, Z. L., Dai, W., Li, Y. J., and Deng, H. W. (1999). Involvement of capsaicin-sensitive sensory nerves in early and delayed cardioprotection induced by a brief ischaemia of the small intestine. Naunyn Schmiedebergs Arch. Pharmacol. 359, 243-247.

Tapuria, N., Junnarkar, S. P., Dutt, N. Abu-Amara, M., Fuller, B., Seifalian, A. M., and Davidson, B. R. (2009). Effect of remote ischemic preconditioning on hepatic microcirculation and function in a rat model of hepatic ischemia reperfusion injury. HPB (Oxford) 11, 108-117.

Tapuria, N., Kumar, Y., Habib, M. M. Abu, A. M., Seifalian, A. M., and Davidson, B. R. (2008). Remote ischemic preconditioning: a nove protective method from ischemia reperfusion injury-a review. J. Surg. Res. 150, 304-330.

Thielmann, M., Kottenberg, E., Boengler, K., Raffelsieper, C., Neuhaeuser, M., Peters, J., Jakob, H., and Heusch, G. (2010). Remote ischemic preconditioning reduces myocardial injury after coronary artery bypass surgery with crystalloid cardioplegic arrest. Basic Res. Cardiol. 105, 657-664.

Tokuno, S., Hinokiyama, K., Tokuno, K., Lowbeer, C., Hansson, L. O., and Valen, G. (2002). Spontaneous ischemic events in the brain and heart adapt the hearts of severely atherosclerotic mice to ischemia. Arterioscler. Thromb. Vasc. Biol. 22, 995-1001.

Tsubota, H., Marui, A., Esaki, J., Bir, S. C., Ikeda, T., and Sakata, R. (2010). Remote postconditioning may attenuate ischaemia-reperfusion injury in the murine hindlimb through adenosine receptor activation. Eur. J. Vasc. Endovasc. Surg. 40, 804-809.

Venugopal, V., Hausenloy, D. J., Ludman, A., Di Salvo, C., Kolvekar, S., Yap, J., Lawrence, D., Bognolo, J., and Yellon, D. M. (2009). Remote ischaemic preconditioning reduces myocardial injury in patients undergoing cardiac surgery with cold-blood cardioplegia: a randomised controlled trial. Heart 95, 1567-1571.

Venugopal, V., Laing, C. M., Ludman, A., Yellon, D. M., and Hausenloy, D. (2010). Effect of remote ischemic preconditioning on acute kidney injury in nondiabetic patients undergoing coronary artery bypass graft surgery: a secondary analysis of 2 small randomized trials. Am. J. Kidney Dis. 56, 1043-1049.

Verdouw, P. D., Gho, B. C., Koning, M. M., Schoemaker, R. G., and Duncker, D. J. (1996). Cardioprotection by ischemic and nonischemic myocardial stress and ischemia in remote organs. Implications for the concept of ischemic preconditioning. Ann. N. Y. Acad. Sci. 793, 27-42.

Waldow, T., Alexiou, K., Witt, W., Albrecht, S., Wagner, F., Knaut, M., and Matschke, K. (2005). Protection against acute porcine lung ischemia/reperfusion injury by systemic preconditioning via hind limb ischemia. Transpl. Int. 18, 198-205.

Walsh, S. R., Nouraei, S. A., Tang, T. Y., Sadat, U., Carpenter, R. H., and Gaunt, M. E. (2010). Remote ischemic preconditioning for cerebral and cardiac protection during carotid endarterectomy: results from a pilot randomized clinical trial. Vasc. Endovascular Surg. 44, 434-439.

Wang, W. Z., Stepheson, L. L., Fang, X. H., Khiabani, K. T., and Zamboni, W. A. (2004). Ischemic preconditioning-induced microvascular protection at a distance. $J$ Reconstr. Microsurg. 20, 175-181.

Wang, Y., Xu, H., Mizoguchi, K., Oe, M., and Maeta, H. (2001). Intestinal ischemia induces late preconditioning against myocardial infarction: a role for inducible nitric oxide synthase. Cardiovasc. Res. 49, 391-398.

Wei, M., Xin, P., Li, S., Tao, J., Li, Y., Li, J., Liu, M., Zhu, W., and Redington, A. N. (2011). Repeated remote ischemic postconditioning protects against adverse left ventricular remodeling and improves survival in a rat model of myocardial infarction. Circ. Res. 108, 1220-1225.

Weinbrenner, C., Nelles, M., Herzog, N., Sarvary, L., and Strasser, R. H. (2002). Remote preconditioning by infrarenal occlusion of the aorta protects the heart from infarction: a newly identified non-neuronal but PKC-dependent pathway. Cardiovasc. Res. 55, 590-601.

Weinbrenner, C., Schulze, F., Sarvary, L., and Strasser, R. H. (2004). Remote preconditioning by infrarenal aortic occlusion is operative via deltalopioid receptors and free radicals in vivo in the rat heart. Cardiovasc. Res. 61, 591-599.

Wever, K. E., Warle, M. C., Wagener, F. A., Van Der Hoorn, J. W., Masereeuw, R., Van Der Vliet, J. A., and Rongen, G. A. (2011). Remote ischaemic preconditioning by brief hind limb ischaemia protects against renal ischaemia-reperfusion injury: the role of adenosine. Nephrol. Dial. Transplant. 26, 3108-3117.

Wolfrum, S., Schneider, K., Heidbreder, M., Nienstedt, J., Dominiak, P., and Dendorfer, A. (2002). Remote preconditioning protects 
the heart by activating myocardial PKCepsilon-isoform. Cardiovasc. Res. 55, 583-589.

Wu, Y. N., Yu, H., Zhu, X. H., Yuan, H. J., Kang, Y., Jiao, J. J., Gao, W. Z., Liu, Y. X., and Lou, J. S. (2011). Noninvasive delayed limb ischemic preconditioning attenuates myocardial ischemia-reperfusion injury in rats by a mitochondrial K(ATP) channeldependent mechanism. Physiol. Res. 60, 271-279.

Xia, Z., Herijgers, P., Nishida, T., Ozaki, S., Wouters, P., and Flameng, W. (2003). Remote preconditioning lessens the deterioration of pulmonary function after repeated coronary artery occlusion and reperfusion in sheep. Can. J. Anaesth. 50, 481-488.

Xiao, L., Lu, R., Hu, C. P., Deng, H. W., and Li, Y. J. (2001). Delayed cardioprotection by intestinal preconditioning is mediated by calcitonin gene-related peptide. Eur. J. Pharmacol. 427, 131-135.

Yuan, H. J., Zhu, X. H., Luo, Q., Wu, Y. N., Kang, Y., Jiao, J. J., Gao, W. Z., Liu, Y. X., and Lou, J. S. (2010). Noninvasive delayed limb ischemic preconditioning in rats increases antioxidant activities in cerebral tissue during severe ischemia-reperfusion injury. J. Surg. Res. PMID: 21195427. [Epub ahead of print].

Zhao, Z. Q., Corvera, J. S., Halkos, M. E., Kerendi, F., Wang, N. P., Guyton, R. A., and Vinten-Johansen, J. (2003). Inhibition of myocardial injury by ischemic postconditioning during reperfusion: comparison with ischemic preconditioning. Am. J. Physiol. Heart Circ. Physiol. 285, H579-H588.

Zhao, Z. Q., Nakamura, M., Wang, N. P., Velez, D. A., Hewan-Lowe, K. O., Guyton, R. A., and Vinten-Johansen,
J. (2000). Dynamic progression of contractile and endothelial dysfunction and infarct extension in the late phase of reperfusion. $J$. Surg. Res. 94, 133-144.

Zhao, Z. Q., Velez, D. A., Wang, N. P., Hewan-Lowe, K. O., Nakamura, M., Guyton, R. A., and Vinten-Johansen, J. (2001). Progressively developed myocardial apoptotic cell death during late phase of reperfusion. Apoptosis 6 , 279-290.

Zhou, Y., Fathali, N., Lekic, T. Ostrowski, R. P., Chen, C., Martin, R. D., Tang, J., and Zhang, J. H. (2011). Remote limb ischemic postconditioning protects against neonatal hypoxic-ischemic brain injury in rat pups by the opioid receptor/Akt pathway. Stroke 42, 439-444.

Conflict of Interest Statement: The authors declare that the research was conducted in the absence of any commercial or financial relationships that could be construed as a potential conflict of interest.

Received: 04 January 2012; paper pending published: 17 January 2012; accepted: 04 February 2012; published online: 20 February 2012

Citation: Lim SY and Hausenloy DJ (2012) Remote ischemic conditioning: from bench to bedside. Front. Physio. 3:27. doi: 10.3389/fphys.2012.00027

This article was submitted to Frontiers in Clinical and Translational Physiology, a specialty of Frontiers in Physiology.

Copyright (c) 2012 Lim and Hausenloy. This is an open-access article distributed under the terms of the Creative Commons Attribution Non Commercial License, which permits non-commercial use, distribution, and reproduction in other forums, provided the original authors and source are credited. 